\title{
Comparison of Scheimpflug imaging parameters between steep and keratoconic corneas of Caucasian eyes
}

This article was published in the following Dove Press journal:

Clinical Ophthalmology

I April 2016

Number of times this article has been viewed

\author{
Tukezban Huseynova' \\ Farah Abdulaliyeva ${ }^{2}$ \\ Michele Lanza ${ }^{3}$ \\ 'Briz-L Eye Clinic, ${ }^{2}$ National \\ Ophthalmology Center, Baku, \\ Azerbaijan; ${ }^{3}$ Second University of \\ Naples, Caserta, Campania, Italy
}

Correspondence: Tukezban Huseynova Briz-L Eye Clinic,

Maqsud Alizadeh 46, AZI I06,

Baku, Azerbaijan

Tel +994503082662

Email tukezban@gmail.com
Purpose: To compare the keratometric and pachymetric parameters of healthy eyes with those affected by steep cornea and keratoconus (KC) using Scheimpflug camera.

Setting: Briz-L Eye Clinic, Baku, Azerbaijan.

Design: A cross-sectional study.

Methods: In this study, $49 \mathrm{KC}$ (Amsler-Krumeich stage 1) eyes and 36 healthy eyes were enrolled. A complete ophthalmic evaluation and a Scheimpflug camera scan were performed in every eye included in the study. Tomographic parameters such as parameters from the front and back cornea, maximum keratometry reading (Kmax), corneal volume (CV), anterior chamber volume $(\mathrm{ChV})$, anterior chamber depth (ACD), anterior chamber angle (AC angle), keratometric power deviation (KPD), maximum front elevation (Max FE), and maximum back elevation (Max BE), as well as pachymetric progression indices (PPI), Ambrosio relational thickness (ART), index of surface variance (ISV), index of vertical asymmetry (IVA), center keratoconus index (CKI), index of height asymmetry (IHA), index of height decentration (IHD), and radius minimum (RM) were collected and statistically compared between the two groups.

Results: PPI, ART, ISV, IVA, CKI, IHA, IHD, and RM parameter values were significantly different $(P<0.05)$ between the $\mathrm{KC}$ and healthy eyes. There were no significant differences in $\mathrm{K}$ mean and $\mathrm{Q}$ values of the frontal corneal parameters, as well as in Kmax, AC angle, RM, back, and front astigmatism, between stage 1 keratoconic and normal Caucasian eyes with steep cornea. All other parameters such as $\mathrm{K}$ mean and Q values of the back corneal parameters, Max FE, Max BE, ACD, ChV, and CV showed significant differences between the groups $(P<0.05$ for all $)$

Conclusion: Scheimpflug imaging is able to detect corneal morphological differences between stage $1 \mathrm{KC}$ eyes and healthy eyes with steep cornea, in Caucasians.

Keywords: Scheimpflug camera, Scheimpflug measurements, keratoconus, corneal tomography, Ambrosio relational thickness

\section{Introduction}

Keratoconus $(\mathrm{KC})$ is a progressive corneal ectatic disorder that may have a variable expression in early stages, with subtle signs and borderline abnormal features that are difficult to detect. ${ }^{1-3}$ Progressive thinning and steepening of the keratoconic cornea has its onset at puberty. As the cornea steepens, the amount of astigmatism increases, causing a distortion of the image which reduces visual acuity of affected patients. ${ }^{4}$ Although $\mathrm{KC}$ can be easily diagnosed with corneal topography, it is rather more difficult to rule out subclinical KC before surgery. ${ }^{5}$ Detection of subclinical $\mathrm{KC}$ or forme fruste $\mathrm{KC}$ among refractive surgery candidates is important because kerato-refractive procedures 
may worsen their condition. ${ }^{5}$ Placido disk-based topography systems are sensitive for detecting the subtle changes of topography on the anterior corneal surface. They provide an accurate assessment of anterior corneal irregularities in the early stages of $\mathrm{KC},{ }^{5}$ however, are limited exclusively to the anterior corneal surface. Slit-imaging technology was an improvement in corneal imaging, as it could provide a measurement of not only the anterior corneal surface but also the posterior surface, and it was additionally able to define the spatial relationship between the two and characterize corneal architecture in three dimensions. Using the Pentacam, a rotating Scheimpflug imager, Ambrosio et $a l^{6}$ have previously reported on the use of pachymetric progression indices (PPI) and the concept of relational thickness in differentiating $\mathrm{KC}$ and healthy corneas by comparing with single-point thickness values. In particular, the study demonstrated that Ambrosio relational thickness (ART) parameters had the best receiver operating characteristics as a test, and ART cutoffs for $\mathrm{KC}$ eyes were determined. ${ }^{6}$

$\mathrm{KC}$ is a complex condition that involves both external factors, such as allergies and eye rubbing, and genetics factors. $^{7-9}$ Severity of the disease has been shown to be associated with family history and ethnic origin. ${ }^{10-12}$ In the Middle East, consanguineous marriages are currently leading to a high prevalence of $\mathrm{KC} .{ }^{13}$

The purpose of this study was thus to analyze the keratometric and pachymetric properties of keratoconic corneas of Caucasian eyes with the Scheimpflug imaging camera and to study the usefulness of ART and PPI in differentiating $\mathrm{KC}$ from normal eyes with steep cornea. To our knowledge, this is the first study which compares the KC eyes and healthy ones with steep corneas in the Caucasian population.

\section{Patients and methods}

The study was approved by a local ethical committee of The National Eye Center named after academician Zarifa Aliyeva, (Baku, Azerbaijan) and was conducted according with Helsinki Declaration principles. Informed consent was obtained from every participant prior to examination and patient anonymity was preserved. $\mathrm{KC}$ was diagnosed according to Amsler-Krumeich criteria and classification. ${ }^{14}$ Healthy eyes were enrolled after a complete eye visit and OCULUS Pentacam HR (Oculus Optikgeräte GmbH, Wetzlar, Germany) scan, and to be included in the study group, anterior corneal power had to be $\geq 45 \mathrm{D}$. Participants were excluded from the study if they had previous eye trauma, corneal or intraocular surgery, glaucoma, corneal scarring, severe eye dryness, current corneal infections, were using topical medications, and were pregnant or nursing.
Soft contact lens users were included in the study after discontinuation of lens wear for at least 7 days.

Parameters retained for the analysis were keratometry readings; topographic astigmatism and asphericity for the anterior and posterior corneal surfaces; pachymetry; cornea volume; anterior chamber volume, angle, and depth; topometric indices; data from corneal thickness spatial profiles; and Belin-Ambrosio-enhanced ectasia display. Corneal thickness is defined as the thinnest point in the corneal thickness map. Corneal volume is reported as the volume of the cornea in a diameter of $10 \mathrm{~mm}$, centered on the anterior corneal apex. Anterior chamber depth is defined as the distance from the corneal endothelium to the anterior surface of the lens capsule. The anterior chamber volume is calculated from the endothelium down to the iris and lens over a $12 \mathrm{~mm}$ diameter centered on the anterior corneal apex. The default angle displayed is the smallest angle in the horizontal position calculated from the Scheimpflug image. For elevation data measurement, the best-fit sphere (BFS) served as a reference body using the float option and the diameter of the reference surface was $8 \mathrm{~mm}$. Front and back elevation difference values were taken as the differential changes in corneal elevation between BFS and the enhanced BFS obtained with the Belin-Ambrosio display (BAD) software. Progression index is calculated as the average progression value at different pachymetric rings, referenced to the mean curve.

The Pentacam calculates a PPI for every $1^{\circ}$ meridian along the complete $360^{\circ}$, starting at the thinnest point. The average of all meridians and the ones with lowest and highest values are presented. The pachymetric index will be higher if the cornea gets thicker in a more accentuated pattern from the thinnest point out to the periphery. The average, minimum, and maximum PPIs were recorded. ART was calculated by the following formulae:

$$
\underset{(\text { ART-Avg })}{\text { Average ART }}=\frac{\text { Minimum corneal thickness }}{\text { Average PPI }}
$$

$$
\underset{(\text { ART-Max })}{\text { Maximum ART }}=\frac{\text { Minimum corneal thickness }}{\text { Maximum PPI }}
$$

Corneal parameters such as index of surface variance (ISV), index of vertical asymmetry (IVA), keratoconus index $(\mathrm{KI})$, central keratoconus index (CKI), index of height asymmetry (IHA), index of height decentration (IHD), and also pachymetric indices such as the PPI and the ART index may be used as additional tools in differentiating $\mathrm{KC}$ from healthy eyes with steep corneas. 


\section{Statistical analysis}

Statistical analysis was performed using SPSS software (version 11.0; SPSS Inc., Chicago, IL, USA). Shapiro-Wilk test was used to examine the normality of study variables. The data were not normally distributed; therefore, the nonparametric Mann-Whitney $U$-test (Wilcoxon rank sum test) was used to compare each parameter between the two groups. A $P$-value less than 0.05 was considered statistically significant. The correlation test was evaluated by Spielman correlation coefficient.

\section{Results}

Data were collected from a total of 85 participants, $49 \mathrm{KC}$ patients and 36 healthy subjects. The mean age of study subjects was $23.77 \pm 7.67$ years, ranging from 12 to 55 years, while that of the control group was $23.19 \pm 4.52$ years, ranging from 18 to 38 years. All the patients were Caucasians. Table 1 shows the mean keratometric and pachymetric values of both groups. While most keratometric and pachymetric readings showed significant differences between the study and control groups, central astigmatism (frontal and back), Kmax, and anterior chamber angle values did not indicate significant differences. Table 2 shows the comparison of topometric and pachymetric indices between the groups. The mean ART values for the normal group were 427.72 and $523.43 \mu \mathrm{m}$ for ART-Max and ART-Avg, respectively. In the KC group, the mean values were 248.74 and $346.83 \mu \mathrm{m}$ for ART-Max and ART-Avg, respectively. The comparison of topometric

Table I Keratometric and pachymetric measures and the difference between groups

\begin{tabular}{|c|c|c|c|}
\hline \multirow[t]{2}{*}{ Parameters } & \multirow{2}{*}{$\begin{array}{l}\text { Keratoconus eyes, stage I } \\
\text { Mean } \pm \text { SD, range }\end{array}$} & \multirow{2}{*}{$\begin{array}{l}\text { Healthy eyes, steep corneas } \\
\text { Mean } \pm \text { SD, range }\end{array}$} & \multirow[t]{2}{*}{$P$-value } \\
\hline & & & \\
\hline \multicolumn{4}{|l|}{ Cornea front } \\
\hline \multirow[t]{2}{*}{$\mathrm{K}$ mean, $\mathrm{D}$} & $47.20 \pm 1.65$ & $45.56 \pm 1.02$ & 0.08 \\
\hline & $(40.90-47.20)$ & $(41.80-47.80)$ & \\
\hline \multirow[t]{2}{*}{ Central astig, D } & $-1.32 \pm 2.10$ & $-1.8 I \pm I .15$ & 0.23 \\
\hline & $(-7.00$ to 3.10$)$ & $(-5.20$ to 0.60$)$ & \\
\hline \multirow[t]{2}{*}{$Q$ value } & $0.56 \pm 0.25$ & $0.48 \pm 0.19$ & 0.07 \\
\hline & $(-0.04$ to 1.06$)$ & $(-0.42$ to 0.70$)$ & \\
\hline \multicolumn{4}{|l|}{ Cornea back } \\
\hline \multirow[t]{2}{*}{$K$ mean, $\mathrm{D}$} & $-6.4 I \pm 0.33$ & $-6.56 \pm 0.14$ & 0.021 \\
\hline & $(-7.00$ to -5.60$)$ & $(-7.00$ to -6.30$)$ & \\
\hline \multirow[t]{2}{*}{ Central astig, D } & $0.10 \pm 1.00$ & $0.43 \pm 0.21$ & 0.076 \\
\hline & $(-6.80$ to 1.10$)$ & $(0.20-1.10)$ & \\
\hline \multirow[t]{2}{*}{$Q$ value } & $0.40 \pm 0.38$ & $0.25 \pm 0.23$ & 0.015 \\
\hline & $(-0.66$ to 1.08$)$ & $(-0.23$ to 0.62$)$ & \\
\hline \multirow[t]{2}{*}{ Kmax, D } & $47.24 \pm 2.31$ & $47.04 \pm 1.12$ & 0.771 \\
\hline & $(43.20-51.50)$ & $(43.60-49.40)$ & \\
\hline \multirow[t]{2}{*}{ Pachymetry pupil center, $\mu \mathrm{m}$} & $503.86 \pm 38.96$ & $529.22 \pm 27.22$ & 0.002 \\
\hline & $(4 \mid 8-585)$ & $(484-616)$ & \\
\hline \multirow[t]{2}{*}{ Pachymetry apex, $\mu \mathrm{m}$} & $505.92 \pm 38.73$ & $530.06 \pm 27.71$ & 0.002 \\
\hline & $(422-583)$ & $(485-6 \mid 6)$ & \\
\hline \multirow[t]{2}{*}{ Pachymetry thinnest location, $\mu \mathrm{m}$} & $494.45 \pm 39.52$ & $526.92 \pm 26.94$ & $<0.0001$ \\
\hline & $(4 \mid 3-58 I)$ & $(484-6 \mid 2)$ & \\
\hline \multirow[t]{2}{*}{$C V$} & $58.4 I \pm 3.8 I$ & $61.09 \pm 3.07$ & $<0.000$ I \\
\hline & $(51.70-66.70)$ & $(56.90-70.10)$ & \\
\hline \multirow[t]{2}{*}{$\mathrm{ChV}$} & $200.12+37.05$ & $180.42 \pm 33.46$ & 0.003 \\
\hline & $(105-296)$ & $(125-254)$ & \\
\hline \multirow[t]{2}{*}{$A C D$} & $3.26 \pm 0.32$ & $3.07 \pm 0.28$ & $<0.0001$ \\
\hline & $(2.34-3.95)$ & (2.47-3.59) & \\
\hline \multirow[t]{2}{*}{ AC angle } & $37.99 \pm 5.11$ & $37.56 \pm 5.79$ & 0.525 \\
\hline & $(25.80-53.10)$ & $(21.40-47.10)$ & \\
\hline \multirow[t]{2}{*}{ KPD } & $1.43 \pm 0.30$ & $1.12 \pm 0.18$ & $<0.0001$ \\
\hline & $(1.00-2.00)$ & $(0.90-1.60)$ & \\
\hline \multirow[t]{2}{*}{ Max FE } & $7.75 \pm 0.29$ & $7.42 \pm 0.38$ & $<0.000$ I \\
\hline & (7.10-8.39) & $(6.04-7.99)$ & \\
\hline \multirow[t]{2}{*}{ Max BE } & $6.33 \pm 0.26$ & $6.26 \pm 0.34$ & 0.039 \\
\hline & $(5.79-6.89)$ & $(5.84-7.68)$ & \\
\hline
\end{tabular}

Abbreviations: SD, standard deviation; D, diopters; central astig, central astigmatism; Q value, asphericity in the central $6 \mathrm{~mm}$ on cornea front surface; CV, corneal volume; Kmax, maximum curvature power on front of cornea; $\mathrm{ChV}$, anterior chamber volume; $\mathrm{ACD}$, anterior chamber depth; $\mathrm{AC}$ angle, anterior chamber angle; $\mathrm{KPD}$, keratometric power deviation; Max FE, maximum front elevation; Max BE, maximum back elevation. 
Table 2 Topometric and pachymetric progression indices between groups

\begin{tabular}{|c|c|c|c|}
\hline \multirow[t]{2}{*}{ Parameters } & \multirow{2}{*}{$\begin{array}{l}\text { Keratoconus eyes, stage I } \\
\text { Mean } \pm \text { SD, range }\end{array}$} & \multirow{2}{*}{$\begin{array}{l}\text { Healthy eyes, steep corneas } \\
\text { Mean } \pm \text { SD, range }\end{array}$} & \multirow[t]{2}{*}{$P$-value } \\
\hline & & & \\
\hline \multirow[t]{2}{*}{ ISV } & $35.94 \pm 10.84$ & $21.83 \pm 8.03$ & $<0.0001$ \\
\hline & $(14.00-57.00)$ & $(10.00-43.00)$ & \\
\hline \multirow[t]{2}{*}{ IVA } & $0.34 \pm 0.17$ & $0.12 \pm 0.04$ & $<0.0001$ \\
\hline & $(0.04-0.65)$ & $(0.05-0.25)$ & \\
\hline \multirow[t]{2}{*}{$\mathrm{KI}$} & $1.07 \pm 0.04$ & $1.02 \pm 0.02$ & $<0.0001$ \\
\hline & $(1.00-1.15)$ & $(0.94-1.06)$ & \\
\hline \multirow[t]{2}{*}{ CKI } & $1.01 \pm 0.02$ & $\mathrm{I} .0 \mathrm{I} \pm 0.0 \mathrm{I}$ & 0.036 \\
\hline & $(0.98-1.06)$ & $(0.99-1.02)$ & \\
\hline \multirow[t]{2}{*}{$\mathrm{IHA}$} & $|2.64 \pm| 1.53$ & $5.02 \pm 4.29$ & $<0.0001$ \\
\hline & $(0.40-44.40)$ & $(0.00-16.50)$ & \\
\hline \multirow[t]{2}{*}{ IHD } & $0.03 \pm 0.02$ & $0.01 \pm 0.00$ & $<0.0001$ \\
\hline & $(0.00-0.06)$ & $(0.00-0.02)$ & \\
\hline \multirow[t]{2}{*}{ Rmin } & $7.17 \pm 0.35$ & $7.18 \pm 0.17$ & 0.792 \\
\hline & $(6.55-7.82)$ & $(6.83-7.74)$ & \\
\hline Absolute distance from apex to the thinnest & $0.91 \pm 0.27$ & $0.65 \pm 0.26$ & $<0.0001$ \\
\hline location, mm & $(0.49-2.14)$ & $(0.29-1.4 I)$ & \\
\hline \multirow[t]{2}{*}{ Pachymetric progression indices, minimum } & $1.15 \pm 0.33$ & $0.75 \pm 0.18$ & $<0.0001$ \\
\hline & $(0.64-2.08)$ & $(0.49-\mid .5 I)$ & \\
\hline \multirow[t]{2}{*}{ Pachymetric progression indices, average } & $1.51 \pm 0.32$ & $1.03 \pm 0.16$ & $<0.0001$ \\
\hline & $(0.98-2.27)$ & $(0.75-1.7 I)$ & \\
\hline \multirow[t]{2}{*}{ Pachymetric progression indices, maximum } & $2.16 \pm 0.58$ & $1.26 \pm 0.18$ & $<0.0001$ \\
\hline & $(1.20-3.54)$ & $(0.92-1.89)$ & \\
\hline \multirow[t]{2}{*}{ Ambrosio relational index, average } & $346.83 \pm 94.29$ & $523.43 \pm 80.37$ & $<0.0001$ \\
\hline & $(|97.6|-58 \mid)$ & $(283.04-764)$ & \\
\hline \multirow[t]{2}{*}{ Ambrosio relational index, maximum } & $248.74 \pm 81.12$ & $427.72 \pm 70.10$ & $<0.0001$ \\
\hline & $(121.11-476.23)$ & $(256.08-603.18)$ & \\
\hline
\end{tabular}

Abbreviations: ISV, index of surface variance, value of curvature variation from the mean curvature; IVA, index of vertical asymmetry, compares the curvature of the upper and lower areas; KI, keratokonus index; CKI, center keratoconus index; IHA, index of height asymmetry, compares the upper and lower height values; IHD, index of height decentration, decentration data in the vertical direction; Rmin, radius minimum.

and pachymetric indices between the groups showed significant difference $(P<0.05)$ in every parameter except for cornea minimum radius of curvature between the groups $(P=0.792)$. Figure 1A illustrates the correlation between the mean curvature power ( $\mathrm{K}$ mean), which is widely used to determine the $\mathrm{KC}$ severity, and absolute distance from the corneal apex to the thinnest location for the $\mathrm{KC}$ group

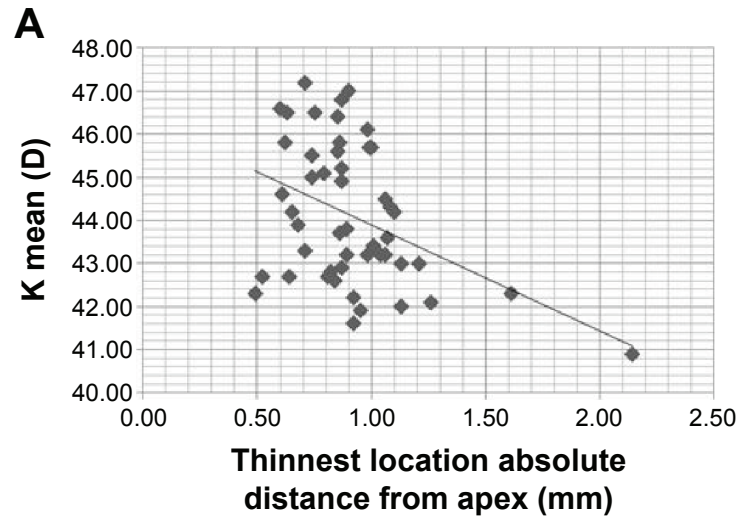

$(r=-0.446, P=0.03)$ and Figure $1 \mathrm{~B}$ for the control group $\left(r_{\mathrm{s}}=-0.116, P=0.32\right)$.

\section{Discussion}

In this study, keratometric, pachymetric, and novel thickness parameters from Pentacam HD tomography are presented and evaluated in healthy and KC Caucasian eyes. Previous studies

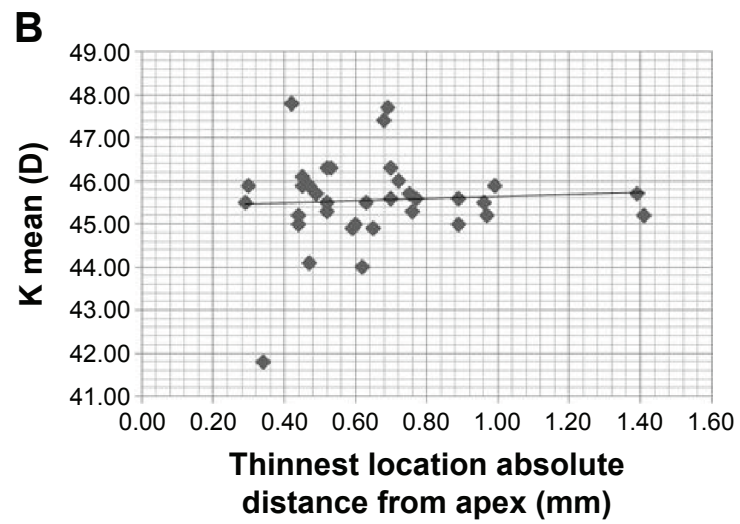

Figure I Correlation between keratometry ( $\mathrm{K}$ mean) and absolute distance from the corneal apex to the thinnest location for the keratoconus (A), and healthy cornea (B) groups. 
have reported significant differences in these parameters between the control and diseased eyes in the Latin American and Middle Eastern populations. ${ }^{6,15}$

As expected, our results showed that pachymetry and corneal keratometric values vary according to the steepness of $\mathrm{KC}$. The thickness of the cornea has been known to decrease as the steepening of the cornea increases. ${ }^{16}$ On the other hand, the steepness of the cornea, as was determined by the $\mathrm{Km}$ value, did not have a significant effect on the corneal volume, neither for the normal steep cornea $(r=-0.065$, $P=0.69)$ nor for the $\mathrm{KC}$ eyes $\left(r_{\mathrm{s}}=0.303, P=0.06\right)$. This is consistent with the findings of Mannion et al, ${ }^{17}$ who found that the corneal volume of mild, moderate, and severely affected patients with $\mathrm{KC}$ significantly differed in the central part only ( 3 and $5 \mathrm{~mm}$ ). Our results regarding the anterior chamber depth were also similar to previous findings. ${ }^{18} \mathrm{In}$ relation to the $\mathrm{KC}$ presence, there was a significant difference in the anterior chamber depth (ACD) but not in the chamber volume, although the eyes affected more severely showed increased values. However, our results showed significant difference in ACD and chamber volume between the groups. Additionally, a correlation was found between $\mathrm{ACD}$ and $\mathrm{Km}$ but only for the KC eyes $\left(r_{\mathrm{s}}=0.449, P=0.003\right)$.

The BAD is an integrated parameter in the Pentacam that combines elevation-based and comprehensive pachymetric corneal evaluation in an all-inclusive display. The BAD displays each parameter and individually reports them as a standard deviation and then reports a final overall reading that is based on a regression analysis to maximize the separation of normal corneas from those with KC. ${ }^{19} \mathrm{Fam}$ and Lim showed that anterior corneal elevation parameters are clinically relevant measures for detecting $\mathrm{KC}$ and suspected $\mathrm{KC}$ eyes. ${ }^{20}$ Previous studies reported that anterior and posterior elevations were the most effective parameters for the diagnosis of KC. ${ }^{21}$ Ambrosio et $\mathrm{al}^{6}$ introduced the analysis of corneal thickness spatial profiles and demonstrated significant differences in absolute thickness and percentage thickness increase as a function of distance from the thinnest point between normal and KC eyes. ${ }^{22}$ The ART is a novel combined parameter that combines the thickness and pachymetric distribution and it was reported to have a sensitivity of $100 \%$ and a specificity of $96.5 \%$ in discriminating $\mathrm{KC}$ from normal corneas. ${ }^{6}$

There are several limitations in the present study. The sample size of the study group is relatively small. As such, while the results validate the usefulness of Pentacam in differentiating keratoconic from normal eyes in Caucasians, the sample size is too small to establish population norms for the measured parameters. The power of the study was not calculated. There was also a higher proportion of males than females in the study group. However, there is no current evidence of differing clinical presentations of $\mathrm{KC}$ between male and female patients, and thus, this is unlikely to skew the results of this study. In a recent study conducted by Ruisenor Vazquez et $\mathrm{al}^{23}$ in a non-Asian population, Pentacam Scheimpflug imaging tomography was found to be able to detect most subclinical $\mathrm{KC}$ cases with unremarkable topography.

The results of our study, even though they should be confirmed with larger population of patients, showed that pachymetric indices such as PPI and the ART are useful tools for differentiating stage 1 keratoconic and healthy steep corneas in the Caucasian subjects.

This study demonstrated significant differences in keratometric and pachymetric parameters between two groups of Caucasian population. The findings also support the usefulness of ART in $\mathrm{KC}$ diagnosis.

\section{Disclosure}

The authors have no competing/conflicting interests to declare.

\section{References}

1. Rabinowitz YS. Keratoconus. Surv Ophthalmol. 1998;42(4): 297-319.

2. Saad A, Gatinel D. Topographic and tomographic properties of forme fruste keratoconus corneas. Invest Ophthalmol Vis Sci. 2010;51(11) 5546-5555.

3. Klyce SD. Chasing the suspect: keratoconus. Br J Ophthalmol. 2009; 93(6):815-819.

4. Patel A, Shah S. Corneal degenerations and keratoconus. Optometry Today. 2012;52(21):49-53.

5. Orucoglu F, Toker E. Comparative analysis of anterior segment parameters in normal and keratoconus eyes generated by Scheimpflug tomography. J Ophthalmol. 2015;2015:925414.

6. Ambrosio R, Caiado ALC, Guerra FP, et al. Novel pachymetric parameters based on corneal tomography for diagnosing keratoconus. $J$ Refract Surg. 2011;27(10):753-758.

7. Karseras AG, Ruben M. Aetiology of keratoconus. Br J Ophthalmol. 1976;60(7):522-525.

8. Gordon-Shaag A, Millodot M, Shneor E. The epidemiology and etiology of keratoconus. Int J Keratoco Ectatic Corneal Dis. 2012;1(1):7-15.

9. Sugar J, Macsai M. What causes keratoconus? Cornea. 2012;31(6): 716-719.

10. Jordan CA, Zamri A, Wheeldon C, Patel D, Johnson R, McGhee CN. Computerized corneal tomography and associated features in a large New Zealand keratoconic population. J Cataract Refract Surg. 2011;37(8):1493-1501.

11. Georgiou T, Funnell CL, Cassels-Brown A, O'Conor R. Influence of ethnic origin on the incidence of keratoconus and associated atopic disease in Asians and white patients. Eye. 2004;18(4):379-383.

12. Mohd-Ali B, Abdu M, Das S, Mohidin N. Ethnicity related to keratoconus: a study with clinical implications. Int Med J. 2011;18(3): $233-236$. 
13. Millodot M, Shneor E, Albou S, Atlani E, Gordon-Shaag A. Prevalence and associated factors of keratoconus in Jerusalem: a cross-sectional study. Ophthalmic Epidemiol. 2011;18(2):91-97.

14. Krumeich JH, Daniel J, Knülle A. Live-epikeratophakia for keratoconus. $J$ Cataract Refract Surg. 1998;24(4):456-463.

15. Muftuoglu O, Ayar O, Ozulken K, Ozyol E, Akıncı A. Posterior corneal elevation and back difference corneal elevation in diagnosing forme fruste keratoconus in the fellow eyes of unilateral keratoconus patients. J Cataract Refract Surg. 2013;39(9):1348-1357.

16. Weed KH, McEwen CJ, Giles T, Low J, McGhee CN. The Dundee University Scottish Keratoconus study: demographics, corneal signs, associated diseases, and eye rubbing. Eye. 2008;22(4):534-541.

17. Mannion LS, Tromans C, O'Donnell C. Reduction in corneal volume with severity of keratoconus. Curr Eye Res. 2011;36(6):522-527.

18. Emre S, Doganay S, Yologlu S. Evaluation of anterior segment parameters in keratoconic eyes measured with the Pentacam system. J Cataract Refract Surg. 2007;33(10):1708-1712.
19. Belin MW, Ambrrosio R. Scheimpflug imaging for keratoconus and ectatic disease. Indian J Ophthalmol. 2013;61(8):401-406.

20. Fam HB, Lim KL. Corneal elevation indices in normal and keratoconic eyes. J Cataract Refract Surg. 2006;32(8):1281-1287.

21. Mihaltz K, Kovacs I, Takacs A, Nagy ZZ. Evaluation of keratometric, pachymetric, and elevation parameters of keratoconic corneas with pentacam. Cornea. 2009;28(9):976-980.

22. Ambrrosio R, Alonso RS, Luz A, Velarde LGC. Corneal-thickness spatial profile and corneal-volume distribution: tomographic indices to detect keratoconus. J Cataract Refract Surg. 2006;32(11):1851-1859.

23. Ruisenor Vazquez PR, Galletti JD, Minguez N, et al. Pentacam Scheimpflug tomography findings in topographically normal patients and subclinical keratoconus cases. Am J Ophthalmol. 2014;158(1):32-40.
Clinical Ophthalmology

\section{Publish your work in this journal}

Clinical Ophthalmology is an international, peer-reviewed journal covering all subspecialties within ophthalmology. Key topics include: Optometry; Visual science; Pharmacology and drug therapy in eye diseases; Basic Sciences; Primary and Secondary eye care; Patient Safety and Quality of Care Improvements. This journal is indexed on

\section{Dovepress}

PubMed Central and CAS, and is the official journal of The Society of Clinical Ophthalmology (SCO). The manuscript management system is completely online and includes a very quick and fair peer-review system, which is all easy to use. Visit http://www.dovepress.com/ testimonials.php to read real quotes from published authors. 